\title{
Analysing Challenges and Strategies in Land Productivity in Sikkim Himalaya, India
}

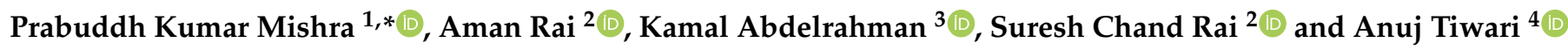 \\ 1 Department of Geography, Shivaji College, University of Delhi, New Delhi 110027, India \\ 2 Department of Geography, Delhi School of Economics, University of Delhi, New Delhi 110027, India; \\ amanrai.ar29@gmail.com (A.R.); scrai@geography.du.ac.in (S.C.R.) \\ 3 Department of Geology and Geophysics, College of Science, King Saud University, \\ Riyadh 11451, Saudi Arabia; khassanein@ksu.edu.sa \\ 4 Discovery Partners Institute, University of Illinois System, Chicago, IL 60606, USA; anujt@uic.edu \\ * Correspondence: prabuddh@shivaji.du.ac.in
}

Citation: Mishra, P.K.; Rai, A.;

Abdelrahman, K.; Rai, S.C.; Tiwari, A Analysing Challenges and Strategies in Land Productivity in Sikkim Himalaya, India. Sustainability 2021, 13, 11112. https://doi.org/10.3390/ su131911112

Academic Editor: Hossein Azadi

Received: 6 September 2021

Accepted: 5 October 2021

Published: 8 October 2021

Publisher's Note: MDPI stays neutral with regard to jurisdictional claims in published maps and institutional affiliations.

Copyright: (c) 2021 by the authors. Licensee MDPI, Basel, Switzerland. This article is an open access article distributed under the terms and conditions of the Creative Commons Attribution (CC BY) license (https:// creativecommons.org/licenses/by/ $4.0 /)$.

\begin{abstract}
Agriculture is the major source of livelihood in rural areas and is considered the backbone of the Indian economy. In Sikkim, agriculture is being practiced by $80 \%$ of the rural population, and having no other major livelihood options has created immense pressure on the farmers and agricultural land. Agriculture sector is under great stress as the farmers are being confronted by various challenges in Sikkim Himalaya in recent years, such as land degradation, climate change and socio-economic problems. Despite the number of indigenous agriculture management methods being practised in Sikkim Himalaya, the agricultural production system is weakening. In this context, this paper presents an analysis of challenges faced by indigenous communities, local farmers and potential sustainable strategies for their management in Rani Khola watershed of Sikkim Himalaya. Data and information were collected by field observation, questionnaire surveys of 300 households, key informant interviews and focus group discussions conducted during 2017-18. Data processing and analysis were carried out with a combination of techniques, such as the application of remote sensing (RS), geographic information system (GIS)-based data processing and descriptive statistics. Major challenges identified in the watershed are water scarcity $(80 \%)$, climate change $(88 \%)$, soil erosion and runoff $(72 \%)$, higher investment cost $(100 \%)$, lack of irrigation facilities $(77 \%)$, fragmentation and size of landholdings (100), human-wildlife conflict (59\%) and pests and disease (60\%). Some possibilities and innovations that could address these problems are the use and retaining of various indigenous soil and water conservation (SWC) measures, diversified farming systems, community involvement in the government development process, better irrigation facilities, strengthening the local economy, coordinated planning between stakeholders and development of market feedback mechanism within the system.
\end{abstract}

Keywords: agriculture; erosion; sustainability; watershed; Sikkim; Himalaya

\section{Introduction}

Mountains cover around one-fifth of the Earth's surface and are home to one-tenth of the world's population. Mountains are diverse in their culture, ethnicity, language, ecological systems, and economy [1]. Himalaya is one of the world's greatest physical features, and it is experiencing a recurring environmental crisis, including environmental degradation, climate change, geometeorological hazards, land use land cover (LULC) change, demographic pressure and the depletion of indigenous knowledge systems [2-4]. These major drivers have not only affected various sources of livelihood in Himalaya but also have widely increased environmental vulnerabilities and struggles of the indigenous communities, many of whom are poor and marginalised [5]. According to FAO figures (2019), one out of every eight people worldwide experiences food insecurity, with the percentage increasing to one out of every two in rural mountain areas [1]. This highlights 
that approximately 300 million people who live in the mountains are suffering from the food security issue. In Sikkim Himalaya, agriculture is the major source of livelihood with no other significant livelihood options. This puts a lot of pressure on farmers and agricultural land. Only $11 \%$ of the total area in Sikkim Himalaya is available for agriculture and more than $60 \%$ of the total population depends on agriculture for their livelihood [6]. Hence, land productivity and agricultural practices play an important role in the social and economic life of people and will continue to do so in the foreseeable future. The majority of the farmers in the Rani Khola watershed are practicing subsistence farming due to small landholdings and environmental challenges. Agricultural production systems are changing rapidly due to shifts in production expenses (input-output cost), consumer demands and increasing concerns for food security and environmental impact $[7,8]$.

An emerging concern in land productivity and sustainable agriculture systems is to promote strategies that are sustainable and also capable of addressing environmental challenges, food and nutritional security and cost-effective production system for the mountain communities. Smyth and Dumanski (1993) argued that a particular agricultural production system can be suitable only if it simultaneously and over a given period: (i) maintains or enhances production; (ii) reduces the level of production risk; (iii) protects the resource base and the natural environment; (iv) is economically viable; and (v) is socially acceptable, and they regarded these as the five pillars of sustainability in an agricultural production system [9]. A similar observation was also put forward in the context of sustainable agriculture by Sassenrath et al. (2009), and the focus was on fulfilling communities' need, sustaining natural resources, efficient resource use, cost-effective farming and overall wellbeing of farmers and society [10]. Aligning with the mentioned definition, sustainable agriculture deals with a system which profitable and replicable, risk-free, utilises local raw materials, conserves soil and water resources, enhances the overall productivity of the land and integrates farmers' indigenous knowledge. To achieve these sustainability goals, agriculture is to be diversified with integrated mixed organic, animal husbandry, and adoption of modern scientific and indigenous agricultural practices $[3,8,11,12]$.

Organic farming is characterised by integrated agricultural production and the major emphasis is on profit maximisation, reducing risk and diversification in the agriculture sector. Some agricultural practices provide economic benefits while also conserving natural resources and ecosystem services, such as modulating water quality and quantity, organic waste disposal, soil formation, biological nitrogen fixation, biological diversity maintenance, biotic regulation and contribution to global climatic regulation [13-15], while other forms of agricultural practices degrade natural capital and ecosystems services. Although a particular type of agricultural practice may benefit an individual, it may have negative externalities such as soil erosion, carbon emissions, biodiversity loss and other negative externalities that harm the local and global ecology. Although agricultural techniques benefit both the economy and the environment, environmental services such as biodiversity and soil conservation are frequently overlooked [16]. Failure to understand the economic worth of environmental services provided by various land use systems frequently results in policies that discourage environmentally favourable agricultural methods. As a result, it is critical to recognise both the economic and environmental advantages of farming operations [15,17].

The majority of the past research shows sustainability in the agriculture sector in Sikkim Himalaya $[18,19]$, whereas recent microlevel studies through field surveys and investigations present a good ground of inquiry. Agriculture production per hectare area of various crops is declining slowly. The state is food deficient, and the requirement is fulfilled by importing from neighbouring states. Due to this, the pressure on agricultural land is increasing to fulfil the increasing demand of food. Various drivers of change such as soil erosion, slope terrace failure, landslides, gully erosion, topsoil erosion on barren land and expansion of riverbanks are most prominent issues under environmental challenge, whereas shortage of labour, landholding size, farmyard manure availability, human-wildlife conflict, pest and diseases are posing threats to sustainable agriculture 
system in recent times. Farmers not only face environmental challenges which affect the overall yielding capacity but also several other challenges that accompany them. In the short run, land degradation leads to productivity loss and inadequacy of staple and cash crops, leaving farmers vulnerable directly or indirectly affects agricultural production, food security and livelihood in long run $[12,20]$. Therefore, pro-mountain policies to build the resilience of mountain environments and indigenous communities are proving vital in recent times by bringing together different stakeholders and fostering partnerships with a multisectoral and holistic approach [1].

In this context, the objective of this study was to make a logical enquiry by developing a preliminary field survey and integration of a geospatially based approach to understand land productivity and agricultural production system. The major research problems that guided our research were:

1. Identify major drivers influencing land productivity in the study area.

2. Analyse major challenges in agriculture faced by the indigenous people/farmer.

3. Which type of innovative solution is being employed correctly for the greatest change in land productivity?

To answer these research problems and fulfil the objectives, field survey, descriptive statistics, remote sensing and geographical information system (RS and GIS) and Statistical Package for the Social Sciences (SPSS) software were utilised. For further analysis, ecological zone-specific data and narratives are combined with information gathered through more general interviews with different key informant groups to address the theme. Several local environmental, climatic, socio-economic and agronomic challenges were reported by farmers in the agricultural production system in the watershed. There has been little or no work in the area of challenges of adaptation. This paper will therefore attempt to address various challenges in the agriculture sector and possible solutions through a field survey and the available literature.

\section{Material and Methods}

\subsection{The Study Area}

The Rani Khola watershed lies within the catchment of the Teesta River occupying an area of $254 \mathrm{~km}^{2}$. It is located in the eastern part of Sikkim Himalaya between the latitudes $27^{\circ} 13^{\prime} 9^{\prime \prime} \mathrm{N}$ to $27^{\circ} 23^{\prime} 51^{\prime \prime} \mathrm{N}$ and longitude $88^{\circ} 29^{\prime} 31^{\prime \prime} \mathrm{E}$ to $88^{\circ} 43^{\prime} 18^{\prime \prime} \mathrm{E}$ (Figure 1). Rani Khola is one of the major rivers draining the area, and the watershed is named after this river which finally drains to Teesta River. Climatically, the watershed is dominated by subtropical to alpine climatic conditions with four distinct seasons. The average temperature ranges between $4{ }^{\circ} \mathrm{C}$ during the winter and $22{ }^{\circ} \mathrm{C}$ during the summer season. The watershed shows a good profile of verticality and elevation ranges from 300 to $4100 \mathrm{~m}$ above mean sea level. The geological and structural control of topography is a dominant feature of this area. The watershed region is composed of the rocks of the Central Crystalline Gneiss Complex of the Proterozoic Era [21]. The watershed geology is characterised by rock formations, i.e., Gorubathan Formation, Chungthang Formation (Paro), Lingtse Granite Gneiss, Darjeeling Gneiss, Everest Limestone, Kanchenjunga Augen Gneiss, Calc Silicate rock with interbanded Quartzite, Garnet Staurolite bearing pelitic schist and thrust faults along Lingtse Granite Gneiss. The geomorphic unit occupies a significant area in the eastern section of the watershed and presents various erosional landforms, i.e., three tier terraces, - gorges, valleys, heavily dissected hillside slope, landslide slopes as well as highly incised meandering and straight channel course. The valley is characterised by the presence of a series of breaks in its longitudinal profile. Primary sources of water in the watershed are springs, streams (Dhara) and small rivers (Khola) through the surface and subsurface water flows originating mostly from the unconfined aquifers. Sikkim's soils are classified as inceptisols (42.83\%), entisols (42.52\%) and mollisols $(14.64 \%)$ by the National Bureau of Soil Survey and Land Use Planning (NBSSLUP). Damthang, Khedi, Sajong are some of the dominant soil series found in this watershed. Subtropical forest and cardamom agroforestry have loamy soils while paddy cropland has clayey loam soil [22]. 
The watershed is characterised by diverse human-nature interaction. The majority of the area in the watershed is rural, and about $29.07 \%$ of the total population are cultivators or agricultural labourers, whereas the total agricultural land available for cultivation is $17.63 \%[4]$.

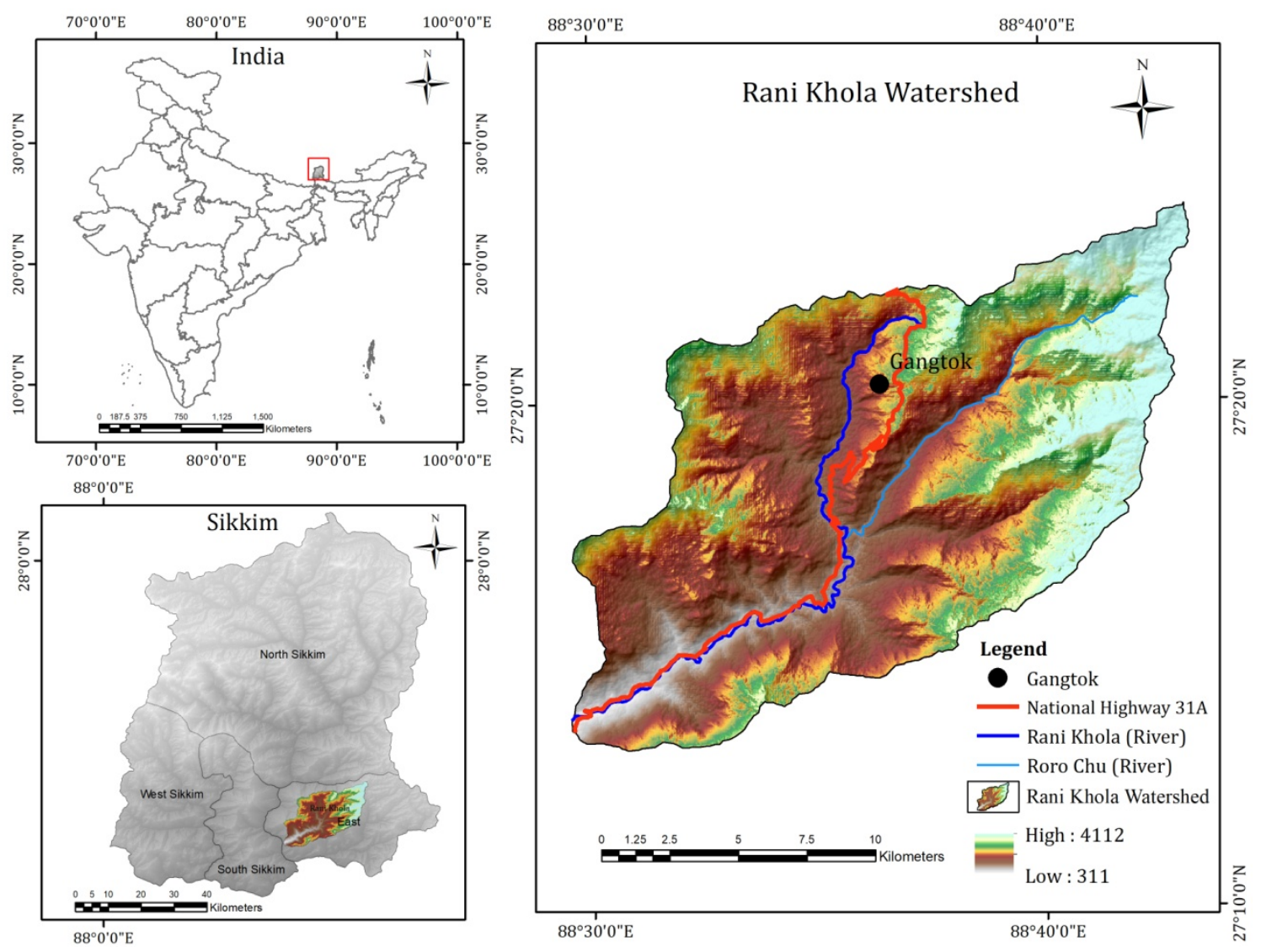

Figure 1. Location map of the Rani Khola watershed.

\subsection{Sources of Data}

Data for the study includes field observation, questionnaire surveys, key informant interviews and focus group discussions conducted during 2017-2018.

\subsubsection{Field Observation}

Initially, a reconnaissance survey was conducted across different agro-ecological zones. Based on the survey result, the agriculture and farming practices, agroforestry systems, and irrigation system, among others, were identified for study.

\subsubsection{Focus Group Discussion (FGD)}

Representative participants from all the high, mid and low ecological zones were selected. From selected villages, four to six focus groups were prepared with a maximum number of five to six participants from farmers. Agriculture Extension Officers, Innovative Farmers, Village Panchayat Heads, and Farmers with large, medium and small landholdings were involved in FGD as they are the main stakeholders in agriculture system and land productivity. FGD aimed to understand their perception, knowledge and idea on the dynamics and driver of agriculture challenge.

\subsubsection{Key Informant Interview (KII)}

KII was conducted from purposefully selected agriculture and rural development officials, elders and natural resource management experts from all ecological zones. The 
interviews were mainly focused on the perception and experience of the community on driving forces in the agriculture sector and strategies for improvement.

\subsubsection{Sampling, Questionnaire Survey and Study Design}

A sample size of 300 households from 9 villages was obtained from the watershed, 100 each from, i.e., low ( $300 \mathrm{~m}$ to $800 \mathrm{~m})$, mid ( $801 \mathrm{~m}$ to $1500 \mathrm{~m})$ and high (1501 $\mathrm{m}$ and above) were selected through stratified random sampling method to select households for the questionnaire survey. In cases of the absence of the selected household head, a random substitute was included. A systematic questionnaire was used to obtain detailed information on the agricultural production system of the sampled households' land. Farmers were requested to answer out a structured questionnaire that took between 30 and $40 \mathrm{~min}$ to complete. Informal interviews were also conducted with each of the following groups: farmers with small, medium and large landholdings, traders cum transporters of agriculture products, the Village Development Committee President and the bank representative of the area. Samples from the selected villages are representative of the study population in the watershed due to the systematic selection technique used, large sample size, wide distribution of respondents over each ecological zone and high response rate.

\subsection{Characteristics of Households}

Agriculture is the main economic activity of the watershed except for the urban area (Gangtok) as a majority of the watershed is rural. The majority of the households in villages still manage a mixed farming system, with primarily subsistence crops and a herd of cows and goats. Table 1 shows the characteristics of respondents from the selected villages. Farmers constitute around $24.03 \%$ of the working population, while agricultural labourers constitute about $5.04 \%$. According to data collected during field survey, $71.33 \%$ of respondent families are nuclear, with an average household size of four people. In all ecological zones, almost $47 \%$ of respondents are marginal farmers with less than 0.5 hectares of land. Farmers with medium-sized landholdings are $30 \%$ in all ecological zones while large landholding farmers are $22.66 \%$ (Table 1). Furthermore, these families tend to have soils that are less productive and have lost most of their previous production capacity. Maize, paddy, ginger, vegetables and cardamom are still the main crops, of which paddy, ginger and vegetables require manure. Other important crops are millet and potato. The main uses of animal traction are for land preparation, and since only a few families own a pair of oxen, they are rented to other families in exchange of labour. The majority of the watershed families do not have fallow seasons in their agricultural rotation. As a result of this, as well as other constraints such as low-quality seeds and low planting density, traditional agriculture methods have been lost, and agricultural productivity levels in this region are often extremely low, making soil and water conservation a pressing concern.

\subsection{Classification of Ecological Zones and Study Villages}

As per the requirement of the study, the watershed was classified into three distinct agro-ecological zones, i.e., high, medium and low based on the altitude, climate, major crops type and irrigation sources (Figure 2). Surveyed villages are plotted on the ecological zone map. Each agro-ecological zone is characterised by differences in cropping patterns, crop productivity levels and land management practices. The area under the low ecological zone falls under tropical climate, which covers the smallest area in the watershed, while the mid ecological zone falls in the subtropical and high ecological zone in temperate climate covering the largest area of the watershed. Out of the total geographical area of the watershed $254.64 \mathrm{~km}^{2}$ (25,464 ha), 13,819 ha (54.27\%) was under the high zone, followed by 10,230 ha $(40.17 \%)$ under the middle zone and 1415 ha $(5.56 \%)$ in the lower zone. Table 2 outlines the most important geographical, climatic, cultural and socio-economic differences among the ecological zones. 
Table 1. Characteristic of Surveyed Households in all ecological zones $(n=300)$.

\begin{tabular}{|c|c|c|c|c|c|}
\hline \multirow[b]{2}{*}{ S. No. } & \multirow{2}{*}{\multicolumn{2}{|c|}{ Parameters }} & \multicolumn{3}{|c|}{ Ecological Zone } \\
\hline & & & \multirow{2}{*}{$\begin{array}{c}\begin{array}{l}\text { Low }(\%) \\
(n=100)\end{array} \\
72 \\
\end{array}$} & \multirow{2}{*}{$\begin{array}{c}\begin{array}{c}\text { Mid (\%) } \\
(n=\mathbf{1 0 0})\end{array} \\
87 \\
\end{array}$} & \multirow{2}{*}{$\begin{array}{c}\begin{array}{c}\text { High (\%) } \\
(n=100)\end{array} \\
69\end{array}$} \\
\hline \multirow{2}{*}{1.} & \multirow{2}{*}{$\begin{array}{c}\text { Respondents of } \\
\text { Households Surveyed }\end{array}$} & Male & & & \\
\hline & & Female & 28 & 13 & 31 \\
\hline \multirow{3}{*}{2.} & \multirow{3}{*}{ Age of the Respondents } & Between 30 and 45 years & 13 & 9 & 16 \\
\hline & & Between 46 and 60 years & 37 & 58 & 57 \\
\hline & & More than 61 years & 50 & 33 & 27 \\
\hline \multirow{2}{*}{3.} & \multirow{2}{*}{ Family Structure } & Nuclear & 75 & 68 & 71 \\
\hline & & Joint & 25 & 32 & 29 \\
\hline \multirow{3}{*}{4.} & \multirow{3}{*}{ Education of Household Head } & Illiterate & 9 & 7 & 5 \\
\hline & & Up to senior secondary Level & 45 & 61 & 71 \\
\hline & & Graduation and above & 44 & 32 & 24 \\
\hline 5. & Average Size of Housel & (Person/household) & 4.3 & 4.1 & 3.9 \\
\hline \multirow{3}{*}{6.} & \multirow{3}{*}{ Operational Size of Holding (ha) } & Marginal $(<0.5)$ & 47 & 49 & 46 \\
\hline & & Medium (0.5-1) & 35 & 26 & 29 \\
\hline & & Large $(>1)$ & 18 & 25 & 25 \\
\hline \multirow{3}{*}{7.} & \multirow{3}{*}{ Livelihood Sources } & Agriculture & 65 & 56 & 60 \\
\hline & & $\begin{array}{l}\text { Agriculture and } \\
\text { Non-agriculture }\end{array}$ & 23 & 29 & 24 \\
\hline & & Services & 12 & 15 & 16 \\
\hline
\end{tabular}

Table 2. Characteristics of ecological zones in the Rani Khola watershed.

\begin{tabular}{|c|c|c|c|c|c|}
\hline $\begin{array}{l}\text { Ecological Zones/ } \\
\text { Climate }\end{array}$ & $\begin{array}{l}\text { Altitude } \\
\text { Range } \\
\text { (m) }\end{array}$ & Area (ha) & Area $(\%)$ & Irrigation Source & Agriculture/Major Crops \\
\hline Low (Tropical) & 311-800 m MSL & 1415 & 5.56 & $\begin{array}{l}\text { Channel irrigation } \\
\text { and rainfed }\end{array}$ & $\begin{array}{l}\text { Subsistence/Commercial } \\
\text { Suitable for subtropical } \\
\text { crops maize, paddy, } \\
\text { cardamom, millet, pulses, } \\
\text { oranges, ginger, peaches, } \\
\text { pears, guava, papaya, } \\
\text { citrus, potato, oilseeds. }\end{array}$ \\
\hline $\begin{array}{c}\text { Medium } \\
\text { (Subtropical) }\end{array}$ & 801-1500 m MSL & 10,230 & 40.17 & $\begin{array}{l}\text { Spring channel } \\
\text { and rainfed }\end{array}$ & $\begin{array}{l}\text { Subsistence/Commercial } \\
\text { Field (paddy, wheat) and } \\
\text { horticultural crops belt } \\
\text { (maize, large cardamom, } \\
\text { barley, oranges, grapefruit, } \\
\text { soybeans, peas, beans, } \\
\text { potato, ginger) }\end{array}$ \\
\hline High (Temperate) & 1501-4112 m MSL & 13,819 & 54.27 & rainfed & $\begin{array}{c}\text { Subsistence/Commercial } \\
\text { Large cardamom, maize, } \\
\text { buckwheat, potatoes, } \\
\text { peas, apples }\end{array}$ \\
\hline
\end{tabular}

Meters $=(\mathrm{m})$, hectares $=($ ha) , mean sea level $=($ MSL $)$.

\subsection{Data Interpretation and Analysis}

Data processing and analysis were carried out using a combination of techniques, such as the application of remote sensing, GIS-based data processing and descriptive statistics. Data collected through qualitative methods (FGD, KII and personal observation) were analysed through descriptive statistics. Secondary data sources, such as climate, official reports and published materials, were also used to support the analysis of KII and FGD. With the help of SPSS software, descriptive statistics were utilised to investigate general trends within the dataset, while a one-way analysis of variance was employed to test the research expectations. One-way ANOVA analysis ( 0.05 or $5 \%$ level of significance) was performed to identify the significant difference in challenges among low, mid and high ecological zones. 


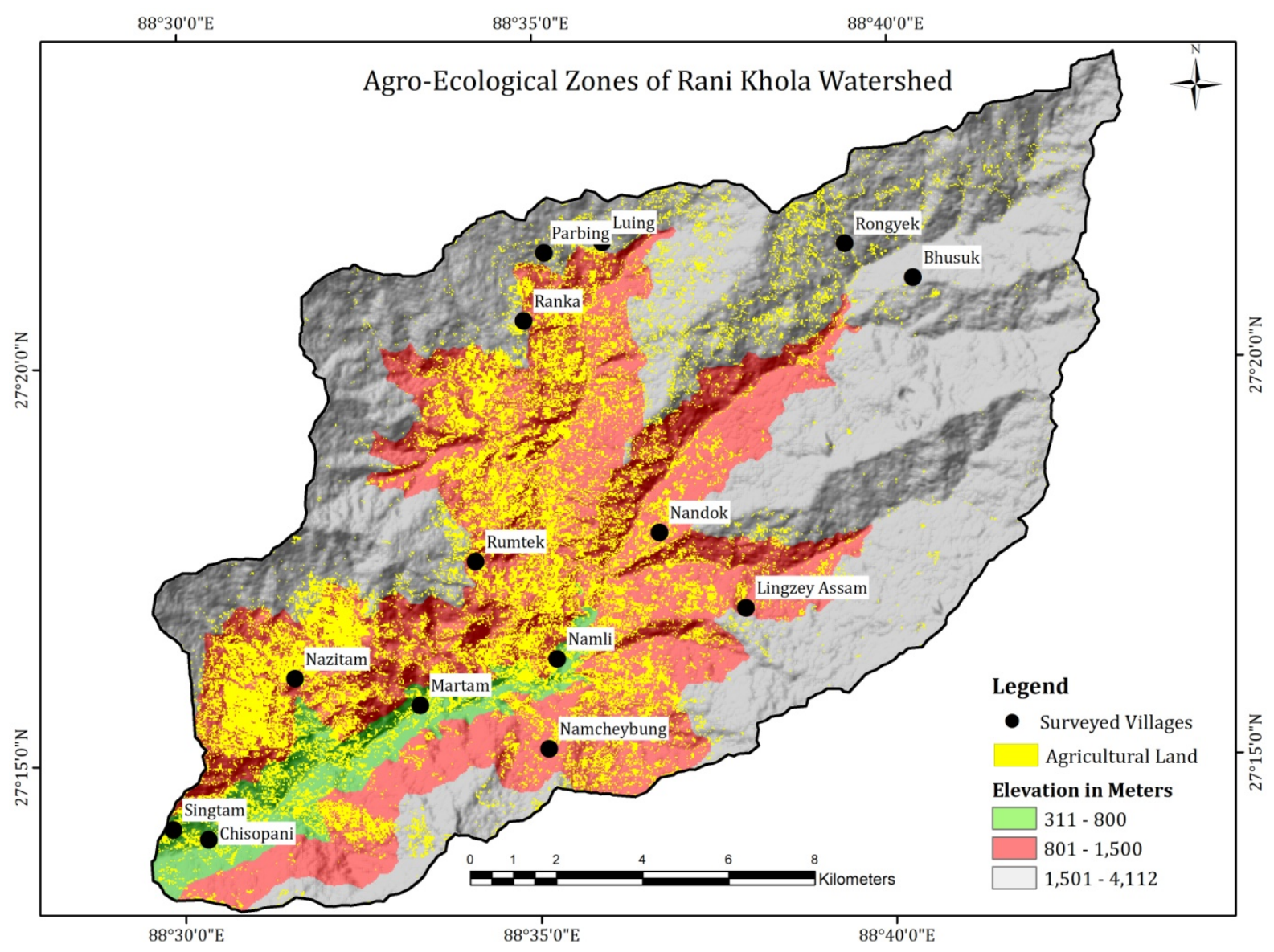

Figure 2. Ecological zones and surveyed villages of the watershed.

\section{Result and Discussion}

\subsection{Major Drivers}

In Rani Khola watershed, the majority of the farmers are practicing subsidence farming on their small and fragmented farmlands with limited access to modern agricultural machines. The land is under immense pressure and maintaining land productivity is a challenging task. Existing poverty, socio-economic conditions, limited resources, climate variability, soil erosion due to higher slope, mismanagement of agricultural land, limited means of irrigation, seasonal water scarcity and methods of cultivation are the major derivers of land productivity in the watershed. These drivers influence agricultural output and farmer livelihood in the watershed. Some of the drivers are interconnected. The state of agricultural productivity in the watershed can easily discourage farmers and other stakeholders. Furthermore, as the status of climate change worsens, the challenges to agricultural productivity are increasing.

\subsection{Major Challenges}

Looking at the complexities of the various challenges farmers face, they may be grouped into three major categories, namely environmental challenges, socio-economic challenges and agronomic challenges. The environmental challenges include climatic challenges such as erratic rainfall, cold waves, hailstorm, frost, water scarcity, loss of soil due to landslides and pollution caused by emerging industries. The socio-economic challenges include small and fragmented landholdings, existing poverty, higher investment cost, lack of alternative sources of income. The agronomic challenges include problems related to cultivation and production such as soil erosion, low production, pests and disease, human-wildlife conflict and loss of indigenous ecological knowledge (IEK). See the Table 3 bellow. 
Table 3. Environmental challenges faced by farmers in the watershed.

\begin{tabular}{ccc}
\hline S. No. & Major Environmental Challenges & Frequency \\
\hline 1. & Seasonal water scarcity & Regular \\
\hline 2. & Hailstorm & Regular \\
\hline 3. & Cold wave & Occasional \\
\hline 4. & Frost & Occasional \\
\hline 5. & Landslides & Regular \\
\hline 6. & Acid rain & Occasional \\
\hline
\end{tabular}

One-way ANOVA at $p<0.05$ level of significance has revealed that there is no significant difference among various challenges in the selected ecological zone of the watershed.

\subsubsection{Environmental Challenges}

Climatic Challenges: Temperature and Rainfall

There is a considerable variation in the climatic conditions in the watershed (temperature and rainfall) throughout the year. About $83 \%$ of the households that participated in the questionnaire survey reported that they had experienced temperature increase, while the remaining $17 \%$ were either ignorant about the issue or did not respond. A similar observation was also recorded for rainfall where the majority of the respondents reported the unpredictable pattern and uneven distribution of rainfall. By and large, climate factors affect agriculture in a significant manner. About $88 \%$ of farmers in all ecological zones were aware and had experienced changing climate and responded that erratic rainfall patterns, temperature rise, cold waves, hailstorm and frost had intensified (Table 4) and affected agricultural production and net revenue. Heavy hailstorm is reported to destroy the roof of greenhouses, which makes them unusable for crops. Some of these challenges are very frequent, while others are less noticeable (Table 5). Due to changing climate, there is variation in rainfall patterns, as reported by the farmers, and it is correlated with the Indian Meteorological Department (IMD) data [23,24]. The significant impact of climate change on biodiversity, hydrology, agriculture and livelihood has been reported in Sikkim Himalaya $[23,25,26]$. According to farmers, the erratic rainfall, decline in seasonal snowfall in the high elevation zone of the watershed and declining large cardamom production are the major climate change indicators of the watershed. Decline in large cardamom production due to changing climate has also been reported all over Sikkim by various studies $[27,28]$. Large cardamom is the major cash crop of the state and nearly $52 \%$ of the farmers during the questionnaire survey reported that practicing large cardamom-based agroforestry is now becoming difficult.

\section{Water Scarcity / Availability for Irrigation}

The farmers in the watershed have never faced a situation such as drought; however, the scarcity of water during peak winter and summer is becoming a major problem. Despite receiving adequate rainfall during the monsoon season, springs of the watershed do not recharge enough, due to the lack of sponge action and higher runoff, to last the whole year. In the Himalayan mountains, springs are the primary source of water for the majority of the rural households but are now not available to communities for drinking purposes and homestead farming $[29,30]$. This water is also used for irrigation purposes by households. Springs are recharged by rainwater infiltration and subsurface flow. About $80 \%$ of the households that participated in the questionnaire agreed that despite various conservation practices promoted by the government and adopted by local communities, water scarcity in the winter and summer seasons is a major concern among farmers (Table 4). 
Table 4. Major challenges faced by farmers in Rani Khola watershed.

\begin{tabular}{|c|c|c|c|c|}
\hline \multirow[b]{2}{*}{ Major Challenges } & \multicolumn{4}{|c|}{ Ecological Zones } \\
\hline & $\begin{array}{c}\text { Low }(n=100) \\
(\%)\end{array}$ & $\begin{array}{c}\operatorname{Mid}(n=100) \\
(\%)\end{array}$ & $\begin{array}{c}\operatorname{High}(n=100) \\
(\%)\end{array}$ & Mean \\
\hline \multicolumn{5}{|c|}{ (1) Environmental Challenges } \\
\hline Changing climate & 91 & 85 & 89 & 88.3 \\
\hline Water scarcity/availability for irrigation & 75 & 80 & 85 & 80 \\
\hline Soil erosion and runoff & 67 & 71 & 79 & 72.3 \\
\hline Pollution caused by emerging industries & 56 & 61 & 49 & 55.3 \\
\hline \multicolumn{5}{|c|}{ (2) Socio-economic Challenges } \\
\hline Small and fragmented landholdings & 100 & 100 & 100 & 100 \\
\hline Existing poverty & 72 & 67 & 79 & 72.6 \\
\hline Higher investment cost & 100 & 100 & 100 & 100 \\
\hline Lack of alternative source of income & 91 & 87 & 81 & 86.3 \\
\hline \multicolumn{5}{|c|}{ (3) Agronomic Challenges } \\
\hline Farmyard manure/green manure & 53 & 57 & 55 & 55 \\
\hline Low productivity & 41 & 53 & 47 & 47 \\
\hline Pests and disease & 60 & 62 & 59 & 60.3 \\
\hline Human-wildlife conflict & 52 & 59 & 67 & 59.3 \\
\hline $\begin{array}{l}\text { Loss of indigenous knowledge on } \\
\text { management practice }\end{array}$ & 27 & 33 & 29 & 29.3 \\
\hline
\end{tabular}

Table 5. Analysis of variance (ANOVA) findings for challenges in agriculture production in each ecological zone of the Rani Khola watershed of Sikkim Himalaya.

\begin{tabular}{|c|c|c|c|c|c|c|c|}
\hline Ecological Zones & Mean & SS & df & MS & F & $p$-Value & F Crit \\
\hline Low & 68.07 & & & & & & \\
\hline Mid & 70.38 & 53.12820513 & 4 & 13.28205128 & 0.027444307 & 0.99 & 2.64 \\
\hline High & 70.69 & & & & & & \\
\hline
\end{tabular}

Sum of Squares $=(\mathrm{SS})$, degrees of freedom $=(\mathrm{df})$, mean sum of squares $=(\mathrm{MS})$, F-statistic $(\mathrm{F}), \mathrm{F}$ critical $=(\mathrm{F}$ crit $)$.

\section{Soil Erosion}

Soils in mountain and hilly areas are the foundation for good food production and, by playing a crucial part in the carbon cycle and water management, they aid local communities in mitigating and adapting to climate change [31]. Mountain soils are home to $25 \%$ of all terrestrial biodiversity, including agro-biodiversity, which is important for regionally adapted crops and livestock [31]. Soil is a fragile resource that needs time to regenerate. However, soil erosion in the watershed has been aggravated by landslides and terrace failure in the last few years [32]. Water-induced soil erosion is the most prevalent form of land degradation in Sikkim Himalaya [33]. Soil erosion is the highest in barren land followed by agricultural fallow land [32]. Wherever the surface of the soil is not covered by vegetation, sheet erosion and overland flow are highest, as the watershed is characterised by high mountains with a steep slope. Investing more in agroforestry is the most effective way to reduce soil loss, followed by terraces [34]. Nearly $90 \%$ of the respondent farmers in the watershed practice cultivation on terraces; however, the type of terrace also determines the soil loss. For example, minimum overland flow occurs in reversed terraces followed by levelled terraces, while sloping terraces cannot retain much water, and higher runoff causes high soil loss in the sloping terraces (Table 4). Therefore, more preference should be given to reverse or levelled terraces when constructing terraces [35].

\section{Emerging Industries}

In the last decade, many factories, industrial units and development projects have emerged, and their industrial waste and pollutants such as chemical waste, water polluter and air pollution are causing environmental degradation in the watershed. About $53 \%$ of farmers reported that there is an impact of emerging industries on overall crop production 
(Table 4). Occasional acid rain in the watershed is also an environmental problem reported by farmers during group discussions. Some of the farmers indicated that an increase in industrialisation in the low ecological zone is one of the major factors affecting environmental pollution and is linked with acid rain.

\subsubsection{Socio-Economic Challenges}

Small and Fragmented Landholdings

Population growth and land distribution to newer generations lead to the division of landholdings into fragmented and small landholdings. Due to this, nearly $50 \%$ of the farmers in the watershed are marginal. Small landholdings cause lower net revenue and lower the risk appetite of farmers. Small and fragmented landholdings lead to multiple problems such as higher labour input, transportation cost, irrigation cost and construction measures. Hence, marginal farmers are forced to grow cash crops that require less input cost and yield higher benefits. Crops that have longer payback periods, such as mandarin and large cardamom, are avoided by marginal farmers and have been replaced by crops such as ginger, turmeric, offseason vegetables grown in the greenhouse, etc. However, for long-term sustainable production, higher investment into the soil is necessary.

\section{Existing Poverty}

Existing poverty and the low income of small landholdings farmers are major economic challenges faced by farmers in the watershed. As the majority of the farmers have marginal and medium landholdings, the ability to invest input capital into soil conservation is very limited. Despite this, they use their traditional knowledge and locally available resources to maintain soil fertility. The majority of marginal farmers rely on the agronomic and biological measures of SWC as mechanical measures require more input cost, and returns are expected after an initial period of one to two years. The strong community support and resource base of the watershed also helps to tackle the problem. Community groups help to provide agricultural loans to the farmers and farmers collectively work to build conservation structures that involve higher labour costs, such as infiltration ditches, gully erosion control measures and terraces.

\section{Higher Investments Cost}

The higher investment cost is a major constraint for marginal farmers with small and fragmented landholdings, and due to this, the majority of farmers in the watershed are more inclined towards the lower input and higher revenue crops as well as lower input agronomic measures. Farmers in the watershed still use their traditional tools for farming and the major investment in the field are in the form of labour cost which is often taken care by the local farmer's community support. However marginal farmers are distressed and often do not want to invest in the conservation measures that require higher inputs for long-term sustainable production of crops.

\section{Lack of Alternative Source of Income}

Lack of alternative sources of income for livelihood is another issue for the farmers. Being dependent on single income through agriculture reduces their ability to invest in long-term conservation measures. Poor literacy and unskilled labour force are also one of the major reasons behind unemployment of the rural population of the watershed. Low education is also a drawback for farmers as they are unaware of new agricultural tools and techniques. The majority of household family members of the farmers are either unemployed or self-employed, working in their own small shops, which does not provide sufficient income to sustain their lives without agriculture. 


\subsubsection{Agronomic Challenges}

Farmyard Manure/Green Manure

Livestock is an integral part of the agriculture production system in the watershed. Traditionally, the majority of families maintain livestock, but it has been observed during the field survey that the number of livestock is declining rapidly, which results in reduced manure availability for crops.

\section{Low Production}

Since the ban on chemical fertilizers in 2005, the decline in the production of crops is reported all over the state of Sikkim. The production capacity of land per hectare has declined in Sikkim compared to other Indian states; however, according to farmers, the production has increased over time, and organic farming will help to maintain soil fertility in the long run. To increase the overall production in the long run, investment in soil fertility management along with traditional mixed farming practices is required.

\section{Pests, Diseases and Human-Wildlife Conflict}

The incidences of pests and diseases are frequent in middle and lower ecological zones. Controlling pests and insects is also one of the major problems in some areas that is affecting overall production. Since the ban on chemical fertilizers, farmers are using cow urine and other organic manure and agronomic measures to reduce pests, diseases and weed growth in farms. Increasing the scientific awareness of insects and diseases through government programs could help farmers to tackle the problem before it becomes too late. Respondents from areas closer to forests reported that sometimes their crops are also being destroyed by groups of monkeys.

\section{Strategies for Improved Agriculture and Livelihood Security}

To encourage the adaptation of innovative technologies, there is a need to create awareness and interest among the beneficiaries, and evaluation, trials and demonstration at farmer's fields are also required. In this section, some of the validated innovative technologies suitable for mountain regions are described in detail. It is also not out of place to mention that these innovative technologies have already been demonstrated and evaluated for their utility and effectiveness, including costs. This technical information material will be useful for agriculture extension workers, and development programme managers. Most of the selected technologies (contour hedgerow, biocomposting, low-cost greenhouses and rainwater harvesting systems) have been tested and validated under actual field conditions to observe their cost-effectiveness utility, adaptability and other characteristics by GBPIHED (Sikkim and Northeast Unit).

\subsection{Reverse Sloping Terraces}

Hilly terrain and erratic heavy rainfall are the major causes of soil and water loss in the region and terracing is the best suitable strategy to minimise soil erosion. Terracing is one of the major SWC techniques practiced in Sikkim Himalaya, which is not only environmentally beneficial but also gives higher returns after the initial 2 years $[35,36]$. While constructing terraces, farmers choose the terrace type according to local physiography and raw materials. Constructing reverse terraces having a slope towards the upper wall is more efficient for retaining soil moisture and nutrients, and similar observations were recorded by studies in Nepal Himalaya [37]. The number of farmers practicing terraced agriculture in the watershed is more than $90 \%$; however, reversed terraces are not very popular and are observed only on very steep slopes. Constructing reversed terraces may increase the overall productivity of soil by reducing overland flow and soil nutrient loss.

\subsection{Wall Growing Crops}

Crops that can grow on the terrace walls or steep slopes such as soybean can be used for growing on terrace walls. This will not only protect the soil but also help to increase 
the revenue and utilise the terrace walls. Farmers in the watershed are already practicing vegetative barriers and a variety of grasses are grown on terrace walls and bunds. Growing wall crops such as soybean, ricebean and Napier grass could help to provide extra income to farmers and in strengthening walls to prevent terrace failure during heavy rainfall.

\subsection{Greenhouse/Playhouse}

Polythene-covered houses are a scaled-down version of conventional greenhouses. Cutting down the cost of polyhouses makes them accessible to a large section of users who can grow vegetables, ornamentals, foliage and other plants in them. The offseason vegetables grown in the polyhouse environment are sold at a higher price. Greenhouse/polyhouses are also major opportunities for farmers to generate higher revenue by investing in offseason vegetables. The concept of the greenhouse is being popularised in the watershed by the local agricultural department, and some government-funded greenhouses are also provided to farmers in the watershed (Figure 3A,B).

\subsection{Floriculture and Horticulture}

Through the use of low-cost polyhouses, a major breakthrough has been achieved in vegetable and flower cultivation in Sikkim. Floriculture is among one of the major potential cash crops in the watershed. Cymbidium, orchid, calla lily, rose, carnation and Lilium are the major flower species grown under floriculture. Floriculture has been able to modify the entire concept of horticulture in the watershed, assisting it in its transition from hobby gardening to a profitable venture. Farmers in Sikkim treasure the Sikkim mandarin for its sentimental and economic importance. Large farmers in the watershed are growing various horticultural crops. Turmeric, ginger and vegetables are major horticulture crops cultivated in the watershed, while major horticulture fruits are guava, peach, passionfruit and banana. Infrastructures to support production, post-harvest and marketing should be provided by local authorities integrating all ongoing programmes for sustainable growth of floriculture and horticulture in the watershed.

\subsection{Improved Variety/Seeds of Field Crops}

Farmers in the watershed are using low-yielding varieties of crops, and using highyielding variety seeds (HYV) could increase the overall production and net revenue. These seeds are proven to be able to increase the yield and mature earlier than local seed varieties. However, farmers in the watershed are not using them. The reason behind the non-usage of HYV seeds is their non-popularity, since the majority of the farmers are not aware of the benefits of these types of seeds and those who are aware do not want to use them, due to the taste of crops grown with hybrid or HYV seeds. Fear of failure is also a major reason for the non-adaptation of a new variety of seeds.

\subsection{Rainwater Harvesting Structures}

Even after receiving heavy rainfall during the monsoonal season, the watershed suffers from water scarcity during peak summer and winter seasons. This is due to poor water management. Constructing low-cost rainwater harvesting structures such as infiltration tanks, ponds and low-cost rooftop rainwater harvesting systems could be used for irrigating high-value crops during dry seasons. Rainwater can be stored and used for many agricultural as well as domestic purposes. Many houses in the watershed have already installed rainwater harvesting systems to store the water for domestic and agricultural uses, an example of a low-cost roof rainwater harvesting system is shown in Figure $3 \mathrm{~F}$, where the farmer has used bamboo, plastic bottle and pipe to collect the rainwater from the roof. Infiltration ditches are also constructed by farmers in different parts of the watershed; however, the number of rainwater harvesting systems and infiltration ditches is still insignificant and requires more attention. 


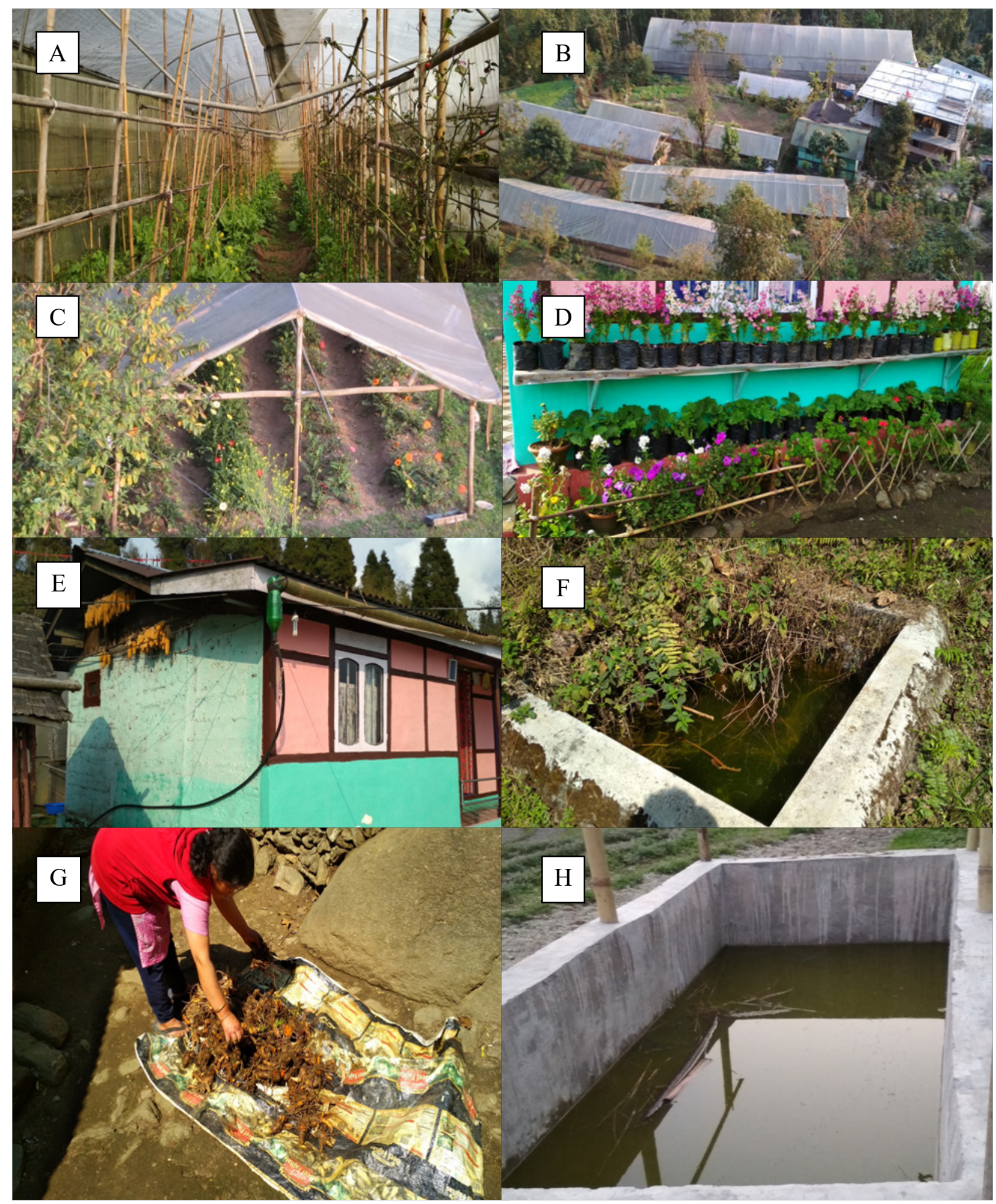

Figure 3. Photographs captured during field survey. Low-cost greenhouse/polyhouse (A,B), floriculture and homestead garden $(\mathbf{C}, \mathbf{D})$, rainwater harvesting structures $(\mathbf{E}, \mathbf{F})$, horticulture crop turmeric $(\mathbf{G})$ and urine collection structure $(\mathbf{H})$.

\subsection{Increasing Production}

The state is deficient in food production due to low per hectare production. Farming practices such as mixed cropping and crop rotation are already practiced by $89 \%$ and $100 \%$ of the respondents, respectively, which shows that the farmers in the watershed are 
already intensively using the agricultural space and time to increase the overall yield per hectare/year.

Using a high-yielding variety of seeds along with mixed cropping and crop rotation can help to increase the overall production. To increase the revenue, focus should be given to traditional cash crops of the region. Adaptation of pest management practices is also important to prevent the crop from pests and disease. Crop rotation and mixed farming naturally help to break the cycle of pest and disease and application of cow urine in the crops help to prevent pests in the field. FYM also helps to increase soil fertility and helps in increasing overall production.

\subsection{FYM Preparation under Shade and Use of Terrace Gravity Flow to Collect Livestock Urine}

FYM and livestock urine play an important role to increase the productivity of the soil and decreases the growth of pests and disease in the crop. To improve the manure quality $(\mathrm{N}, \mathrm{C}, \mathrm{P}, \mathrm{K})$ it should be prepared under the shade to help it mature early. Collecting the livestock urine and storing it is a hectic task for farmers and requires energy and time; however, using the terrace gravity flow to collect the livestock urine could be useful in saving time and energy and conserving urine quantity.

\section{Policy Implication}

The agricultural development in Sikkim Himalaya is guided by many organisations such as the International Mountain Society, FAO and UNEP and has been providing global leadership on sustainable mountain development for decades. While mountain agriculture has made progress, finding new, responsive solutions that directly address mountains in terms of Sustainable Development Goal 2-Zero Hunger-is still a work in progress. Various national and state-level programmes to strengthen the food security, water availability and agricultural sustainability through horticulture and agroforestry have been introduced in the last few decades, such as Horticulture Mission for the northeast and Himalayan states (HMNEH) 2001, National Bamboo Mission 2007, Sikkim Organic State Mission 2005, National Mission on Medicinal Plants (NMMP) 2009, National Food Security Mission 2007 (NFSM), Sikkim Dairy Mission 2009-2012 and Sikkim Poultry Mission 2009-2012. The majority of these programmes have worked on cluster demonstration, seed distribution, distribution of equipment, providing seed storage facility, supporting fodder growth, season-based training and increasing awareness. To conserve water in the region, state governmental policies, such as the Dhara Vikas Yojna, have worked to revive springs and streams that supply drinking water to more than $80 \%$ of the state's rural households. Existing agricultural policies in the state have helped to support the sustainable agricultural approach.

It is the impact of traditional knowledge of farmers and state policies that the dense forest cover in the watershed is increased by $41.76 \mathrm{~km}^{2}$ from 1988 to 2017 as indicated by the LULC analysis [4]. We expect to see more policies and programmes that aim to provide direct benefits to marginal and medium-scale farmers through high-yielding seed varieties, awareness programmes, floriculture and horticulture promotion programmes for small-scale farmers. We also hope to see a greater emphasis on cropping systems in planning and legislation, which will not only help to decrease erosion but also enhance productivity, lower costs and encourage people to manage their land more sustainably.

\section{Conclusions}

The resources and local agricultural knowledge present in the watershed are sufficient to sustain the agriculture system, but problems triggered by climate change, increasingly frequent extreme weather conditions, erosion of soil and in the rainy season, existing poverty, higher input cost, diseases and pest in crops and anthropogenic activities such as inappropriate land management, acidification of soil due to land pollution, acid rain and overpressure on cultivated land are major reasons for declining agricultural productivity. All these reasons are causing shortage of food self-sufficiency in the watershed, which has 
a larger impact on marginal farmers. If the suggested innovative solutions are employed correctly, such as the construction of more reverse sloping terraces to reduce soil erosion, investing in greenhouse/polyhouse-based horticulture, floriculture and cardamom- and mandarin-based agroforestry may fetch long-term sustainable benefits. These benefits can be further strengthened by using improved seed varieties for higher production, constructing rainwater harvesting structures, preparation and production of more FYM, use of terrace gravity flow to collect livestock urine as well as the improved implication of existing state agricultural policies. Popularising the traditional ecological knowledge of farmers in Sikkim Himalaya and their generations of SWC knowledge is needed for sustainable agriculture as well as the ecology of the region. For hundreds of years, farmers of the watershed have been practicing these conservation techniques and even after unfavourable conditions such as steep slopes, erratic rainfall, high soil erosion during monsoon and small terrace sizes, the farmer are able to sustain and generate income. These traditional conservation techniques require more attention from researchers and planners to preserve valuable knowledge and include them in the agricultural policies of the state. Policies should focus on improving and supporting marginal farmers, as they are the ones who need it the most. When making decisions and planning, it is equally important to include the participation of local representatives. It is worth noting how land is maintained is influenced by the thousands of individuals that use it, and progress cannot be accomplished unless the land users themselves are involved in the process.

Author Contributions: Conceptualization, P.K.M.; methodology, P.K.M. and S.C.R.; software, A.R. and A.T.; validation, A.R.; formal analysis, K.A.; investigation, A.T.; resources, A.T.; data curation, K.A. and A.T.; writing—original draft preparation, A.R.; writing—review and editing, P.K.M., S.C.R. and K.A.; supervision, P.K.M. and S.C.R.; project administration, P.K.M. All authors have read and agreed to the published version of the manuscript.

Funding: This research was funded by Indian Council of Social Science Research (ICSSR) New Delhi, India for financial support [F. No 02/298/2016/17/ICSSR/RP] and Researchers Supporting Project number (RSP-2021/351), King Saud University, Riyadh, Saudi Arabia.

Institutional Review Board Statement: Not applicable.

Informed Consent Statement: Informed consent was obtained from all respondents involved in the study.

Data Availability Statement: The data presented in this study are available on request from the corresponding author. The data are not publicly available due to privacy or ethical restrictions.

Acknowledgments: The authors are thankful to the Indian Council of Social Science Research (ICSSR) New Delhi, India for financial support [F. No 02/298/2016/17/ICSSR/RP] to carry out the research. Deep thanks and gratitude to the Researchers Supporting Project number (RSP-2021/351), King Saud University, Riyadh, Saudi Arabia for funding this research article. Authors are also thankful to all the respondents and participants of questionnaire survey, FGD and KII for their inputs and to anonymous reviewers for their valuable comments.

Conflicts of Interest: The authors declare no conflict of interest.

\section{References}

1. FAO. Mountain Agriculture: Opportunities for Harnessing Zero Hunger in Asia; FAO: Bangkok, Thailand, 2019.

2. Dhar, T.N. Land Policies, Land Management and Land Degradation in the Hindu Kush-Himalayas: India; Study Report; ICIMOD: Kathmandu, Nepal, 2000.

3. Sharma, R.; XU, J.; Sharma, G. Traditional agroforestry in the eastern Himalayan region: Land management system supporting ecosystem services. Trop. Ecol. 2007, 48, 189-200.

4. Mishra, P.; Rai, A.; Rai, S.C. Land use and land cover change detection using geospatial techniques in the Sikkim Himalaya, India. Egypt. J. Remote Sens. Space Sci. 2020, 23, 133-143. [CrossRef]

5. Kumar, P.; Rai, S. An overview of exiting contours for promoting different strategies for livelihood security in Sikkim Himalaya. Curr. Res. Environ. Sustain. 2021, 3, 100034. [CrossRef]

6. Agricultural Census. Agriculture Census Division, Department of Agriculture \& Cooperation Ministry of Agriculture New Delhi 2015. 2011. Available online: https:/ /agcensus.nic.in/document/agcensus2010/allindia201011H.pdf (accessed on 12 August 2021). 
7. Chapagain, T.; Raizada, M. Agronomic Challenges and Opportunities for Smallholder Terrace Agriculture in Developing Countries. Front. Plant Sci. 2017, 8, 331. [CrossRef] [PubMed]

8. Hendrickson, J.; Hanson, J.; Tanaka, D.; Sassenrath, G. Principles of integrated agricultural systems: Introduction to processes and definition. Renew. Agric. Food Syst. 2008, 23, 265-271. [CrossRef]

9. Smyth, A.J.; Dumanski, J. An International Framework for Evaluating Sustainable Land Management; World Soil Resources Report No. 73; FAO: Rome, Italy, 1993.

10. Sassenrath, G.F.; Hanson, J.D.; Hendrickson, J.R.; Archer, D.W.; Halloran, J.M.; Steiner, J.J. Principles of dynamic integrated agricultural systems: Lessons learned from an examination of southeast production systems. In Agroecosystem Management for Ecological, Social, and Economic Sustainability; Bohlen, P., Ed.; Advances in Agroecology Series; Taylor and Francis/CRC Press: Boca Raton, FL, USA, 2009.

11. Boller, E.F.; Avilla, J.; Joerg, E.; Malavolta, C.; Wijnands, E.P. Integrated production: Principles and technical guidelines. IOBC WPRS Bull. 2004, 27, 2.

12. Mishra, P.K.; Rai, S.C. Use of indigenous soil and water conservation practices among farmers in Sikkim Himalaya. Indian J. Tradit. Knowl. 2013, 12, 454-464.

13. Paoletti, M.; Pimentel, D.; Stinner, B.; Stinner, D. Agroecosystem biodiversity: Matching production and conservation biology. Agric. Ecosyst. Environ. 1992, 40, 3-23. [CrossRef]

14. Pimentel, D.; Wilson, C.; McCullum, C.; Huang, R.; Dwen, P.; Flack, J.; Tran, Q.; Saltman, T.; Cliff, B. Economic and Environmental Benefits of Biodiversity. BioScience 1997, 47, 747-757. [CrossRef]

15. Björklund, J.; Limburg, K.; Rydberg, T. Impact of production intensity on the ability of the agricultural landscape to generate ecosystem services: An example from Sweden. Ecol. Econ. 1999, 29, 269-291. [CrossRef]

16. Barbier, E.B. The Economics of Land Degradation and Rural Poverty Linkages in Africa. In UNU/INRA Annual Lectures on Natural Resource Conservation and Management in Africa, November 1998; UNU/INRA: Accra, Ghana, 19 November 1998.

17. Ninan, K.N. The Economics of Biodiversity Conservation-Valuation in Tropical Forest Ecosystems; Earthscan Publication: London, UK, 2007.

18. Rai, S.; Sharma, E.; Sundriyal, R. Conservation in the Sikkim Himalaya: Traditional Knowledge and Land-use of the Mamlay Watershed. Environ. Conserv. 1994, 21, 30-34. [CrossRef]

19. Badola, H.K.; Lepcha, J.; Gaira, K.S.; Sinha, S.; Dhyani, P.P. Socio Economic and Bioresource Assessment: Participatory and Household Survey Methods, Tools and Techniques (A Training Manual Based on the Experiences from the Khangchendzonga Landscape, India). GBPNIHESD, Sikkim Unit, Gangtok, India; Highlanders Communications Private Limited: New Delhi, India, 2016.

20. Chiphang, S.; Singh, R. Livelihood Security Determinants of the Organic Farm Household in Sikkim, India: Ordered Logistic Regression Approach. Curr. J. Appl. Sci. Technol. 2020, 138-143. [CrossRef]

21. GSI. Geology and Mineral Resources of Districts of Sikkim; Geological Survey of India: Kolkata, India, 2001; pp. 1-44.

22. Lepcha, N.; Devi, N. Effect of land use, season, and soil depth on soil microbial biomass carbon of Eastern Himalayas. Ecol. Process. 2020, 9, 1-14. [CrossRef]

23. Rahman, H.; Karuppaiyan, R.; Senapati, P.C.; Ngachan, S.V.; Kumar, A. Mid-hills of Sikkim and strategies for mitigating possible. In Climate Change in Sikkim-Patterns, Impacts and Initiatives; Arrawatia, M.L., Tambe, S., Eds.; Information and Public Relations Department, Government of Sikkim: Sikkim, India, 2008; pp. 19-48.

24. Kumar, P.; Sharma, M.; Saini, R.; Singh, G. Climatic variability at Gangtok and Tadong weather observatories in Sikkim, India, during 1961-2017. Sci. Rep. 2020, 10, 15177. [CrossRef] [PubMed]

25. Seetharam, K. Climate change synthetic scenario over Gangtok. In Climate Change in Sikkim-Patterns, Impacts and Initiatives; Arrawatia, M.L., Tambe, S., Eds.; Information and Public Relations Department, Government of Sikkim: Sikkim, India, 2008; pp. 1-18.

26. Sharma, R.; Shrestha, D. Climate perceptions of local communities validated through scientific signals in Sikkim Himalaya, India. Environ. Monit. Assess. 2016, 188,1-11. [CrossRef]

27. Sharma, E.; Rai, S.; Sharma, R. Soil, water and nutrient conservation in mountain farming systems: Case-study from the Sikkim Himalaya. J. Environ. Manag. 2001, 61, 123-135. [CrossRef] [PubMed]

28. Sharma, G.; Partap, U.; Dahal, D.; Sharma, D.; Sharma, E. Declining Large-Cardamom Production Systems in the Sikkim Himalayas: Climate Change Impacts, Agroeconomic Potential, and Revival Strategies. Mt. Res. Dev. 2016, 36, 286. [CrossRef]

29. Tambe, S.; Kharel, G.; Arrawatia, M.; Kulkarni, H.; Mahamuni, K.; Ganeriwala, A. Reviving Dying Springs: Climate Change Adaptation Experiments from the Sikkim Himalaya. Mt. Res. Dev. 2012, 32, 62-72. [CrossRef]

30. Bagchi, D.; Kannaujiya, S.; Champati ray, P.; Taloor, A.; Sarkar, T. A study on spring rejuvenation and springshed characterization in Mussoorie, Garhwal Himalaya using an integrated geospatial-geophysical approach. Remote Sens. Appl. 2021, $23,100588$. [CrossRef]

31. FAO. Understanding Mountain Soils: A Contribution from Mountain Areas to the International Year of Soils; FAO: Rome, Italy, 2015.

32. Mishra, P.K. Assessment of Run-off and Soil Loss under different Land-use Practices in a Himalayan Watershed, India. Am. Res. J. Humanit. Soc. Sci. 2017, 3.

33. Rai, S.C.; Sharma, E. Comparative assessment of runoff characteristics under different land-use pattern within a Himalayan watershed. Hydrol. Process. 1998, 12, 2235-2248. [CrossRef]

34. Rai, S.C.; Sharma, E. Hydrology and nutrient flux in an agrarian watershed of the Sikkim Himalaya, J. Soil Water Conserv. 1998, $53,125-132$. 
35. Mishra, P.K.; Rai, A.; Rai, S.C. Indigenous Knowledge of Terrace Management for Soil and Water Conservation in the Sikkim Himalaya, India. Indian J. Tradit. Knowl. 2020, 19, 475-485.

36. Mishra, P.; Rai, S. A Cost-Benefit Analysis of Indigenous Soil and Water Conservation Measures in Sikkim Himalaya, India. Mt. Res. Dev. 2014, 34, 27-35. [CrossRef]

37. Tamang, D. Indigenous Soil Fertility Management in the Hills of Nepal: Lessons from an East-West Transect; Research Report Series No. 19; Ministry of Agriculture, HMGN/Winrock International: Kathmandu, Nepal, 1992. 